\title{
Hyperferritinemia and inflammation
}

\author{
Kate F. Kernan ${ }^{1,2}$ and Joseph A. Carcillo, ${ }^{1,2}$ \\ 1'Department of Critical Care Medicine, University of Pittsburgh, 3550 Terrace Street, Pittsburgh, PA 15261, USA \\ 2Present address: Division of Pediatric Critical Care Medicine, Faculty Pavilion, Children's Hospital of Pittsburgh, Suite 2000, \\ 4400 Penn Avenue, Pittsburgh, PA 15224, USA \\ Correspondence to: J. A. Carcillo; E-mail: carcilloja@ccm.upmc.edu \\ Received 3 April 2017, editorial decision 19 May 2017; accepted 23 May 2017
}

\begin{abstract}
Understanding of ferritin biology has traditionally centered on its role in iron storage and homeostasis, with low ferritin levels indicative of deficiency and high levels indicative of primary or secondary hemochromatosis. However, further work has shown that iron, redox biology and inflammation are inexorably linked. During infection, increased ferritin levels represent an important host defense mechanism that deprives bacterial growth of iron and protects immune cell function. It may also be protective, limiting the production of free radicals and mediating immunomodulation. Additionally, hyperferritinemia is a key acute-phase reactants, used by clinicians as an indication for therapeutic intervention, aimed at controlling inflammation in high-risk patients. One school of thought maintains that hyperferritinemia is an 'innocent bystander' biomarker of uncontrolled inflammation that can be used to gauge effectiveness of intervention. Other schools of thought maintain that ferritin induction could be a protective negative regulatory loop. Others maintain that ferritin is a key mediator of immune dysregulation, especially in extreme hyperferritinemia, via direct immune-suppressive and pro-inflammatory effects. There is a clear need for further investigation of the role of ferritin in uncontrolled inflammatory conditions both as a biomarker and mediator of disease because its occurrence identifies patients with high mortality risk and its resolution predicts their improved survival.
\end{abstract}

Keywords: ferritin, hemophagocytic lymphohistiocytosis, hemophagocytosis, iron, macrophage activation

\section{Introduction}

Iron is an essential component of hemoproteins, the principle proteins of oxygen transport in the cytochrome system of the electron transport chain, liver metabolism in cytochrome p450s, as well as myoglobin and hemoglobin. As such, maintaining physiologic levels of iron is essential with deficiency leading to impairment of oxidative phosphorylation, oxygen delivery and subsequent metabolic failure. However, toxicity is also possible. In excess, iron can generate toxic free radicals via the Fenton reaction that directly damage cellular proteins, lipids and nucleic acids. Figure 1 illustrates this reaction, where in the presence of hydrogen peroxide-an occasional, but potentially damaging byproduct of aerobic metabolism-ferrous iron $\left(\mathrm{Fe}^{2+}\right)$ is oxidized to ferric $\left(\mathrm{Fe}^{3+}\right)$, producing a hydroxyl radical and hydroxide ion. Subsequently, iron metabolism is tightly regulated and actively sequestered by cells, in part by ferritin molecules to limit induced oxidative stress.

Beyond this protective role in redox biology and iron homeostasis, free serum ferritin is increased in the setting of ongoing inflammation. The precise mechanisms of its induction and downstream effects are the principle topic of this review and likely represent both protective and damaging responses. Evidence supports a role for ferritin in modulating the immune response, via its induction of anti-inflammatory cytokines and limitation of free radical damage. Alternatively, emerging work suggests a potential causative role for ferritin in the inflammatory pathology of disease including rheumatologic, immunologic, malignant and infectious disorders where levels not only track disease activity but may be primary in pathology and are predictive of outcome.

\section{Ferritin in iron homeostasis}

In humans, dietary iron is taken up in two forms: (i) organic heme from meat sources transported by heme carrier protein 1 (HCP1) and (ii) in inorganic iron transported by divalent metal transporter 1 (DMT1) (1). Once they are absorbed into the bloodstream, transferrin binds two iron molecules with extremely high affinity and chaperones their transport in the blood. By complexing with transferrin receptors (TFR1 or TFR2), iron is then able to cross the plasma membrane in receptor-mediated endocytosis (2). In the cytosol, a small fraction of intracellular iron is maintained in the labile iron pool, while the majority is utilized in enzymes or sequestered in ferritin to prevent iron-mediated oxidative damage. 


\section{$\mathrm{Fe}^{2+}+\mathrm{H}_{2} \mathrm{O}_{2} \longrightarrow \mathrm{Fe}^{3+}+\mathrm{OH}^{-}+\mathrm{OH}^{-}$}

Fig. 1. The Fenton redox reaction. Ferrous $\mathrm{Fe}^{2+}$ iron is readily convertible into ferric $3+$ iron, along with the production of free hydroxyl radicals and hydroxide anion. These free radicals become a source of cellular oxidative stress, damaging DNA, lipids and proteins. Ferritin molecules help sequester this free iron, preventing its participation in this reaction and subsequent free radical-mediated cellular damage.

Ferritin itself is a shell protein that sequesters iron in its core. The shell is composed of 24 subunits in variable ratios of heavy and light chain ferritin encoded by the FTH and FTL genes, respectively. The FTH/FTL ratio is tissue- and contextspecific, and dynamically regulated, with FTH becoming more abundant in settings of inflammation. Although incompletely understood, this process is likely related to differential FTH/FTL activity; both types store iron, but FTL does so more readily and is more abundant in tissues like spleen and liver. Its heavy chain counterpart, found predominantly in the heart and kidney, has increased ferroxidase activity, converting ferrous $\mathrm{Fe}^{2+}$ iron into the inert ferric 3+ form, quenching oxidative stress. Although FTL stores iron more efficiently, at least one FTH subunit is required for iron loading into the ferritin shell, and it is likely that all ferritin multimers contain some of each form (3).

These macromolecules are tremendously efficient storage devices: a single ferritin molecule can contain up 4500 molecules of iron and its synthesis is finely tuned to iron levels through a series of feedback loops. Both FTH and FTL mRNA contain an iron response element (IRE) in their 5' untranslated region (UTR), a regulatory stem-loop structure that when bound by iron regulatory proteins 1 or 2 (IRP1 or IRP2) suppresses mRNA translation. IRP affinity for the IRE is increased in settings of low iron, subsequently suppressing ferritin translation (4). Conversely, in the presence of elevated iron levels, IRP1 and IRP2 do not bind IRE as readily and ferritin mRNA synthesis is increased (2).

Expression of the relative ratios of $\mathrm{FTH}$ and FTL subunits is influenced by the inflammatory milieu. Cytokines and paracrine signaling molecules such as nitrogen monoxide (NO) increase the relative FTH content and impact IRE-IRP binding directly. Additionally, they can modulate ferritin expression through IRE-independent mechanisms discussed in more detail later (5-8).

On a cellular level, macrophages act as a major iron sink by directly phagocytizing senescent red blood cells $(9,10)$. This homeostatic function is particularly relevant in conditions of ongoing inflammation where red blood cells have a limited half-life and fragments are more abundant. In vitro, treatment with TNF- $\alpha$ and IL- $1 \alpha$ has been directly shown to shorten RBC half-life (11). In vivo, septic patients have changes in RBC membrane composition $(12,13)$ and intracellular calcium concentration (14), with effects on RBC deformational capacity and rheology (15). External to the RBC, increased cellular adhesion molecule expression, endothelial activation and decreased NO availability contribute to microcirculatory disruption and decreased RBC lifespan (16). All of these increase the need for macrophage-mediated RBC and hemoglobin turnover.

When human macrophages are treated with free hemoglobin, they engulf hemoglobin-haptoglobin complexes via
CD163 and subsequent receptor-mediated endocytosis, triggering a transcriptional antioxidant response that increases ferritin content (17). A schematic representation of this process is shown in Fig. 2. This may be clinically relevant in situations of red cell lysis, where free hemoglobin is released into the blood stream, limiting lipid peroxidation. Heme is then recycled by heme oxygenase 1 (HMOX1), an evolutionarily conserved enzyme that cleaves the protoporphyrin hemering, releasing biliverdin, carbon monoxide and labile Fe (18). Ferritin then sequesters free iron, preventing hemoglobinmediated generation of free radicals (10). Macrophages are then capable of releasing iron through ferroportin (Slc40a1) as substrate for cellular recycling in erythropoiesis $(9,19,20)$, and tissue healing (21). This process is particularly important in endothelial cell health, because of the high concentration of heme molecules in the vascular space and the proximity of macrophages to the endothelium.

As such, ferritin synthesis is regulated by various oxidant and antioxidant stimuli such as glutathione, NO and other reactive oxygen species (22). Perturbation of this homeostatic function has been implicated in the disease pathology of vascular diseases such as diabetes mellitus (23) and atherosclerosis $(24,25)$.

\section{Heavy chain ferritin during inflammation}

At the level of the organism, ferritin protects the host during active infection, limiting the availability of iron to pathogens (26-28). In fact, oral iron supplementation during infection increases mortality in humans (29) and hypoferremia and elevated serum ferritin is common in human populations exposed to high pathogen loads (30). These laboratory abnormalities can be induced experimentally in mice by injection of IL-1 $\alpha$ or TNF- $\alpha$ (31), cytokines with known effects on macrophage iron uptake, storage and recirculation. M1 (classically activated) macrophages induced via treatment with INF- $\gamma$ profoundly change their iron handling phenotype: lowering IRP binding activity, increasing FTH expression, lowering their labile iron pool and decreasing Slc40a1, as they are actively secreting other pro-inflammatory mediators such as TNF- $\alpha(32,33)$. Similarly, Seifert et al. have shown an increase in macrophage synthesis of FTH in co-culture with pathogens (34). This simultaneously limits free iron available to pathogens while minimizing oxidative stress.

Regulation of ferritin synthesis is cytokine responsive at both the transcriptional and translational level in a variety of cells including mesenchymal cells, hepatocytes, monocytes and macrophages $(19,35,36)$. TNF- $\alpha$ - and IL-1 $\alpha$-treated fibroblasts have been shown to increase the FTH fraction in an NF-kB-dependent manner through an IRP/IRE-independent mechanism $(19,37,38)$. Likewise, IL-1 $\beta$ has been shown to increase $\mathrm{FTH}$ expression in hepatocytes, binding to an enhancer region $70 \mathrm{bp}$ from the start codon $(39,40)$.

Similar effects have been seen in macrophages, where INF- $\gamma$ activated U937 cells treated with TNF- $\alpha$ also induced FTH mRNA expression (7). Nrf2, a basic leucine zipper transcription factor that regulates antioxidant protein expression, is recruited to the antioxidant responsive element (ARE) in the FTH promoter region, stimulating its transcription (41). $\mathrm{IL}-1 \beta$ has also been shown to have a direct effect on a $5^{\prime}$ 


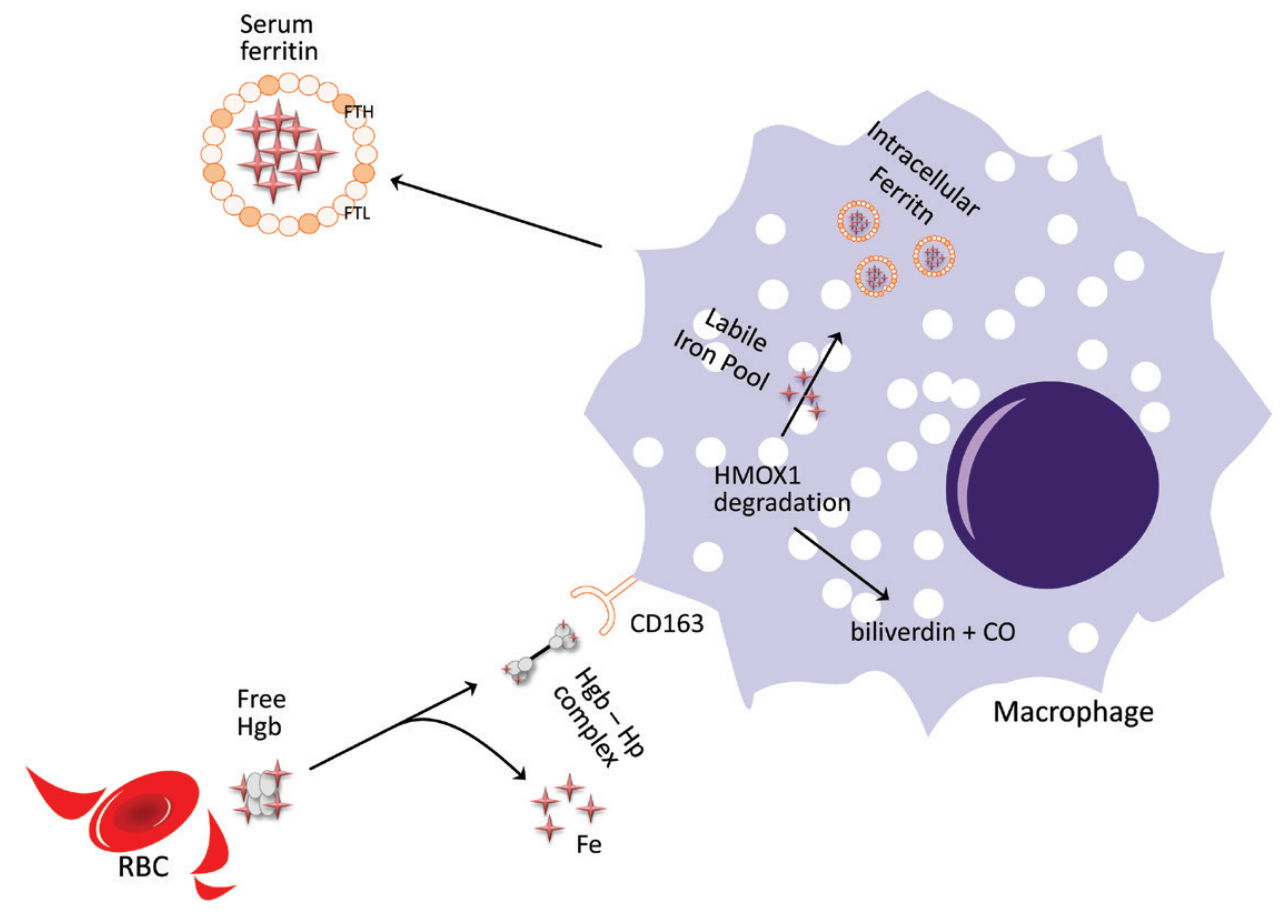

Fig. 2. Ferritin in RBC iron homeostasis. Macrophages phagocytize senescent RBCs directly, as well as taking up circulating hemoglobinhaptoglobin complexes (Hgb-Hp) via CD163 receptor-mediated endocytosis. This allows the macrophage to recycle iron via HMOX1, where hemoglobin is broken down into biliverdin, carbon monoxide and the free iron of the labile iron pool. It can then be incorporated into intracellular ferritin, preventing the formation of toxic free radicals. Once complexed, it is then stable for storage or transport into the plasma circulation.

translational regulatory element rich in $\mathrm{G}$ and $\mathrm{C}$ content and shared among other acute-phase reactants such as haptoglobin and $\alpha 1$-antitrypsin (42). This may offer significant protective advantage, as oxidizing agent, and inflammatory cytokine-induced FTH becomes more abundant during times of active immunologic response, thereby limiting ongoing ironmediated free radical damage. A summary of transcriptional and translational control of FTH expression is shown in Fig. 3.

\section{Sources of serum ferritin in inflammation}

Serum ferritin is a well-known acute-phase reactant, with levels that mirror the degree of acute and chronic inflammation in infectious, rheumatologic, hematologic and malignant disease. In general, serum ferritin has a high ratio of FTL to FTH and is frequently glycosylated, unlike intracellular ferritin (43). The FTL subunit contains a site for $\mathrm{N}$-glycosylation, which is thought to occur as a post-translational modification as the protein moves through the Golgi apparatus en route to its eventual secretion (44). Additionally, the relative contributions of glycosylated and non-glycosylated ferritin to serum levels are also altered during disease. Normally, the glycosylated fraction (GF) of serum ferritin is $~ 50 \%$. However, in adult-onset Still's disease (AOSD), observed elevations in serum ferritin are accompanied by low levels of glycosylation, typically $\leq 20 \%$ (45-48). Similar decreases in GF are seen in cases in the setting of hemophagocytic syndromes regardless of etiology (49-51), drug-induced hypersensitivity reactions $(52,53)$ and severe infections (50). However, the degree of glycosylation may help distinguish underlying pathology. Suggested mechanisms for the decreased GF include saturation of the typical glycosylation mechanisms (46) or direct release from cells following inflammation-related lysis. Early work by Worwood et al. showed that liver damage and subsequent cell lysis caused decreased GF in serum ferritin (54), with similar changes seen in the setting of tumor lysis syndrome and hematologic malignancy $(55,56)$. However, neither of these explanations seem completely adequate, as low GF can persist in AOSD even as symptomatic disease activity and total serum ferritin decrease $(46,57)$.

Hepatocytes (42), Kupffer cells (58), proximal tubular renal cells (59) and macrophages $(3,60,61)$ have all been shown to secrete ferritin in various in vivo and in vitro conditions. Cultured cells release ferritin into surrounding media when grown in the presence of $\mathrm{IL}-1 \beta$ and TNF- $\alpha$ (42). Although it is unlikely that macrophages represent the sole source of serum ferritin, sufficient evidence exists for their role in its generation. Murine macrophages are known to actively secrete ferritin (61). Moreover, mice with macrophage-specific knockouts of IRP2 that are unable to suppress ferritin mRNA synthesis have elevated serum ferritin levels, whereas mice with IRP2 specifically knocked out in hepatocytes or intestinal cells do not (3).

In individuals with hereditary hyperferritinemia cataract syndrome, mutation in the IRE region of the FTL gene results in elevated serum and intracellular ferritin levels in monocytes, indicating that these cells are a key source of serum ferritin (62). In comparison with intracellular ferritin, serum ferritin is iron-poor, suggesting a role beyond iron sequestration for the plasma form (61).

This macrophage-mediated ferritin secretion is directly relevant to human disease. Active secretion of ferritin by 

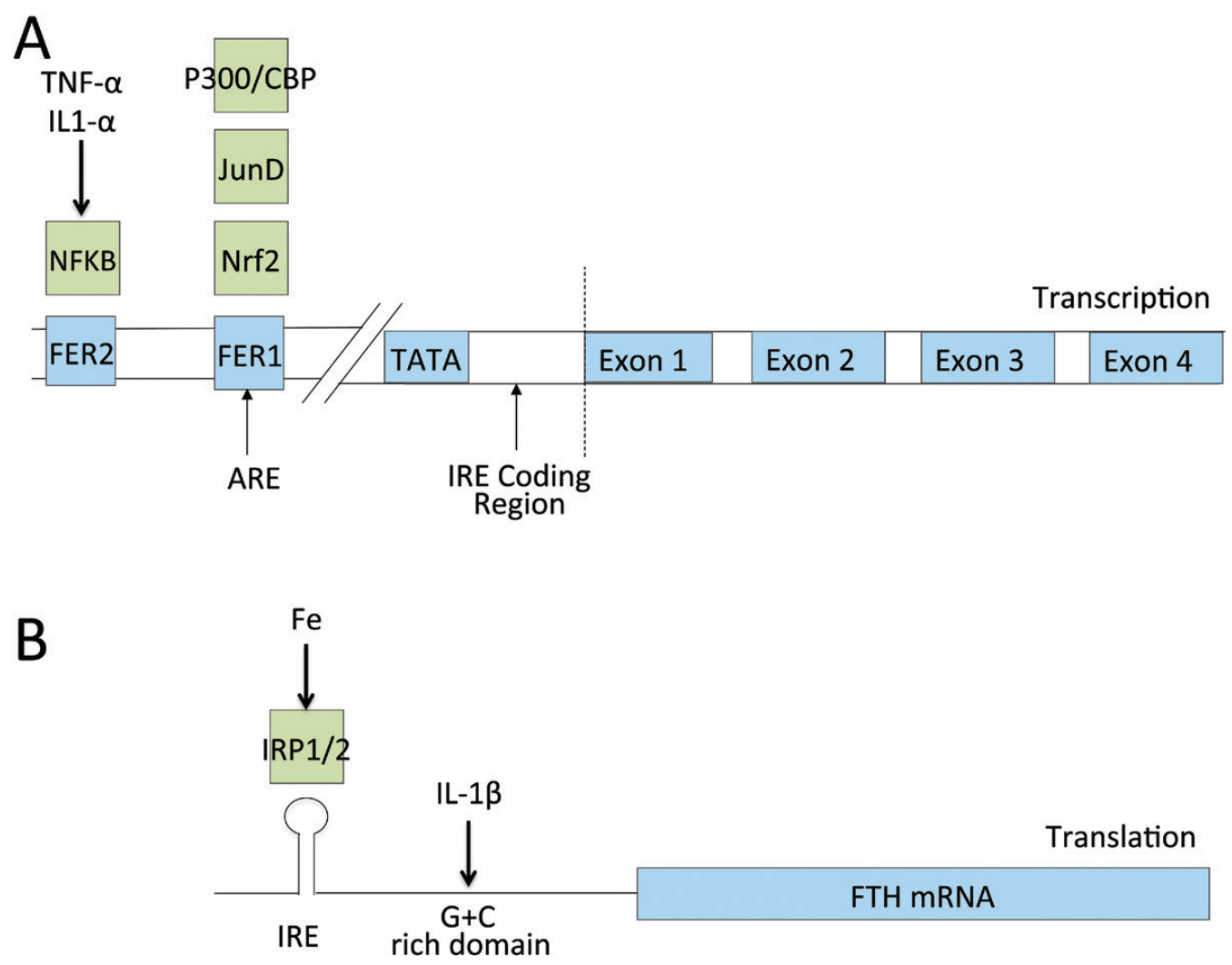

Fig. 3. Schematic of transcriptional and translational regulators of FTH expression. Ferritin expression is a highly regulated process at both the transcriptional and translational levels. (A) At the genome level, FTH ferritin gene expression has been shown to be influenced directly by transcription factors responsive to inflammatory and oxidative states including NF- $\mathrm{BB}$, Nrf2 and JunD. NF- $\mathrm{kB}$ is thought to bind to the regulatory region FER2. P300/CBP, JunD and Nrf2 are thought to influence gene expression through interaction with the ARE, which overlaps with the FER1 promoter region (32-35). (B) The major post-transcriptional regulator of ferritin translation is iron, through its effects on the binding between IRP1 and IRP2 and the IRE in its 5' UTR (14). Additional work has shown direct effects of IL-1ß on FTH mRNA translation (36).

macrophages is seen in recovered bronchoalveolar lavage fluid of smokers in the setting of smoking-related lung inflammation (60). Levels of the soluble CD163 (sCD163) marker of activated macrophages are correlated with serum ferritin in individuals with AOSD or septic shock (63). Post-mortem immunology bone marrow specimens from individuals with septic shock show increased macrophage CD163 and activity, as well as hemophagocytosis in comparison with non-septic controls (64). However, the local and systemic mechanisms of immunomodulation that occur as a result of this active ferritin secretion are incompletely understood.

\section{Immunomodulatory effects of ferritin}

\section{Ferritin as a pro-inflammatory cytokine}

While ferritin levels are known to correlate with inflammatory activity, some postulate a direct causal role for ferritin in mediating inflammatory conditions. Ruddell et al. have explored a causal role for ferritin in the pathology of chronic liver injury and cirrhosis. Their work in activated rat hepatic stellate cells has shown that through binding TIM-2 (T-cell immunoglobulin and mucin domain 2), a rat FTH receptor, ferritin may work as a local cytokine, activating MAPK-triggered NF- $\mathrm{KB}$ in an iron-independent manner. This leads to increased mRNA and protein expression of multiple pro-inflammatory mediators including near 100-fold increases in inducible NO synthase (iNOS), 50-fold increases in IL-1 $\beta$ and RANTES and smaller effects on ICAM1 (65). The relevance of these findings to human pathology is unknown, as TIM-2 does not have a known human ortholog. However, the human receptors TIM1, TIM3 and TIM4 have considerable sequence homology and as such may share similar functions (66).

\section{Ferritin and lymphocyte modulation}

In humans, T and B lymphocytes bind FTH directly, though the precise receptor remains unknown $(36,67)$. In vitro, this binding has immunosuppressive effects impairing T-cell proliferation and B-cell maturation and immunoglobulin production (67-69). Recent work suggests that the inhibitory functions of FTH are largely IL-10 mediated. In the presence of CXCL12, ferritin binds CXCR4 directly and induces IL-10 synthesis (70). This FTH-triggered IL-10 promotes regulatory T-cell differentiation and is postulated as a mechanism for anergy development in tumor development and progression (71). In vivo, FTH inhibits the delayed-type hypersensitivity response (72). Other postulated mechanisms for ferritin-mediated lymphocyte suppression include down-regulation of CD2 (73). All of these may represent an important protective negative 
feedback loops, where ferritin induced by active inflammation and oxidizers limits adaptive immune propagation.

\section{Ferritin in inflammatory human disease}

Hyperferritinemia, regardless of the underlying pathology, is associated with high mortality (74-76). As a marker of significant macrophage activation, individuals manifesting a hyperferritinemic phenotype show a typical pattern of reticuloendothelial system activation and multiple organ dysfunction (74-80). This phenotype is classically described in primary or familial hemophagocytic lymphohistiocytosis (FHLH), a recessive genetic disorder of excessive macrophage activation driven by IFN- $\gamma$ that results from an inability to clear pathogen subsequent to inherited defects of CTL and NK cell-mediated cytolytic killing.

Presenting in infancy, FHLH is caused by homozygous defects of the perforin and granzyme pathways, including PRF1, UNC13D, STX11 and STXBP2, that impair the ability to produce, mobilize and secrete cytolytic granules by CTLs and NK cells - the main mechanism of clearance of infected cells, tumor cells and activated antigen-presenting cells (APCs) $(81,82)$. Thus, FHLH T cells and macrophages form an ineffective dyad, where pro-inflammatory signals are repeatedly amplified secondary to the impaired ability to clear pathogenic stimulation in a feed-forward loop of a cytokine storm. The result is overwhelming systemic inflammation with massive cytokine induction (83).

Patients with inflammatory conditions other than FHLH can also present with macrophage activation syndrome (MAS), including viral or bacterial sepsis, systemic inflammatory response syndrome (SIRS), inherited immunologic disorders and rheumatologic disease, particularly pediatric systemic juvenile idiopathic arthritis (JIA) and AOSD. All are pathobiologically linked through a pattern of extreme hyperferritinemia and elevated cytokines including TNF- $\alpha$, IFN- $\gamma$, IL $1-\beta$, IL-10, IL-12, IL-6 and M-CSF (84-86). A subset of these individuals will go on to develop such extreme systemic immune activation that they manifest multiple organ dysfunction and fulfill five of the eight diagnostic criteria: fever; splenomegaly; cytopenia; elevated triglycerides or decreased low fibrinogen; elevated ferritin; low or absent NK cell activity; hemophagocytosis; and increased soluble IL-2 receptor (sCD25).

In the absence of identifiable HLH-associated gene mutation, these conditions are classified as reactive $\mathrm{HLH}(\mathrm{rHLH})$, as secondary HLH or-in the case of rheumatic disease-as MAS (87). Indeed, other genetic work suggests that complete absence of functional protein in the cytolytic pathway is not necessary to develop this condition, with similar patterns of hyper immune activation being seen in heterozygous adults harboring a single FHLH-associated gene mutation, occasionally described as 'hypomorphic HLH' (88), as well as in those with no identifiable genetic abnormality (89). While FHLH is classically considered an autosomal recessive disorder, requiring inheritance of two aberrant gene copies at a single locus, the disorder may be more completely understood along a spectrum of cytotoxic dysfunction. At one extreme lies early-onset severe autosomal recessive disease with complete penetrance and well-defined genetics, in the middle, heterozygous or 'hypomorphic' disease typified by
$\mathrm{rHLH}$ and MAS and then at the other more complex genetic and likely other acquired and environmental contributions to disease pathology. Our own laboratory has reported the presence of gene mutations outside of the classic cytolytic/ granzyme pathway in patients with septic shock, extreme hyperferritinemia and features of MAS, classically associated with atypical hemolytic uremic syndrome and its ineffective inhibitory complement response and in the cryopyrin-associated periodic syndrome-associated excessive inflammasome response (90) that might influence the hyperferritinemic phenotype in immune signaling and regulation.

Work by Behrens et al. in mouse models demonstrated that repeated TLR9 stimulation with CpG DNA, a common microbial and viral damage-associated molecular pattern (DAMP), in the absence of infection could trigger the MAS phenotype, including hyperferritinemia, independently of lymphocytes (91). This highlights the importance of the APCs in MAS development and serves as a potential pathologic link between infectious trigger, macrophage activation and subsequent hyperferritinemia. Interestingly, in this model, IL-10 blockade led to a fulminant hemophagocytic phenotype.

CpG stimulation may play a key role in the development of organ injury and has been studied extensively in TLR9induced IL-1 $\beta$-mediated liver injury $(92,93)$, a phenotype that can be rescued using IL-1 receptor antagonist (IL-1RA), which blocks binding of IL-1a and IL-1 $\beta$ to their receptor (94). TLR9 stimulation induces inflammasome activation with positive feedback loop production of IL-1 $\beta$ and IL-18 (95). Petrasek et al. also showed that CpG treatment is linked to local induction of IFN- $\gamma$ production (93). As discussed, both IL-1 $\beta$ and IFN- $\gamma$ induce ferritin production through NF- $\mathrm{KB}$ signaling.

Preliminary work in an in vitro leukemic cell lines suggests that ferritin is capable of increasing TLR9 expression as well as other TLRs (95). This finding was also present clinically, where elevated ferritin levels were associated with increased expression of TLR9 on the mononuclear cells of individuals following allogenic bone marrow transplantation. If present in other pathologic settings, this could reinforce a positive feedback inflammation loop. Interestingly, treatment with IL-1a/ $\beta$ receptor blockade improved survival in septic-shock patients with features of MAS (96). Figure 4 shows a working model of this hypothesized role of ferritin in this process, as well as multiple putative therapeutic targets to interrupt the inflammatory cycle including novel applications of glyburide (97), the small-molecule inhibitor of NLRP3 MCC950 (98) and plasma exchange, as well as more targeted therapy.

As hyperferritinemia in clinical medicine is ubiquitous (99), identified in many conditions and treated by different subspecialists, the proposed therapies are equally variable: in sepsis, source control; in rheumatologic illness, anti-inflammation (100, 101); in FHLH or malignancy, cytotoxic therapy; and in some instances, in bone marrow transplantation (102). Subsequently, considerable controversy exists about the best therapeutic approach to hyperferritinemia-associated HLH/ MAS/sepsis multiple organ dysfunction syndrome (MODS). Variable proposed therapies include dexamethasone, etoposide, cyclosporine $A$, anti-thymocyte globulin (ATG), antiINF- $\gamma$ antibody, IL-18-binding protein and $\mathrm{IL}-1 \mathrm{a} / \beta$ receptor blockade (103-107). Such possibilities have been explored with success, including the recent treatment with IL-18 
Working Model of Inflammatory Positive Feedback

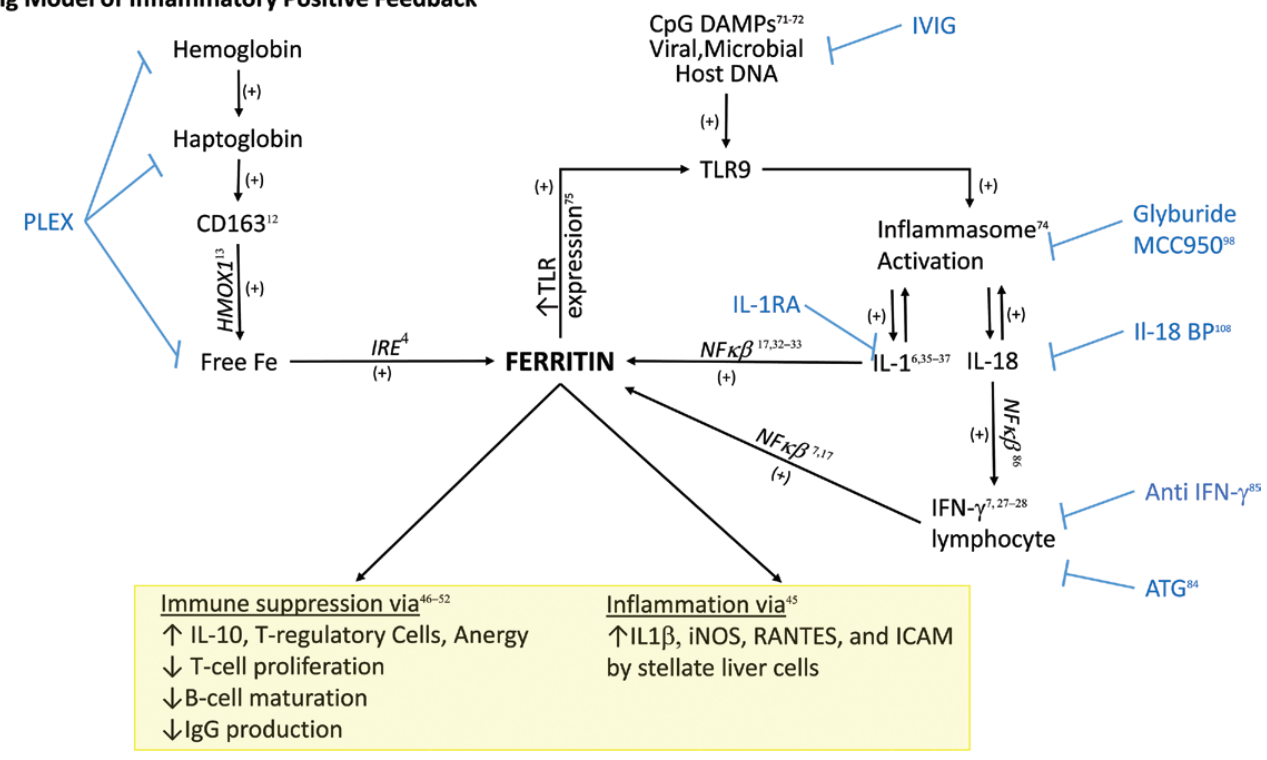

Fig. 4. Proposed ferritin-mediated feed-forward inflammatory loop. In the setting of ongoing infection, CpG DNA from viral or bacterial pathogens triggers TLR9-mediated signaling. This TLR9 stimulation has been shown to activate inflammasome activity, leading to IL-1 $\beta$ and IL-18 production $(71,74)$. IL-1 $\beta$ activation can then in turn increase the translation of FTH mRNA through direct interaction with the $5^{\prime}$ UTR (36). Through ferritin's induction of IL-1 $\beta$ (45) and TLR9 (75), a positive feed back loop would ensue where the generation of ferritin downstream of TLR9 activation would lead to increased amplification of inflammatory signals. Parallel to CpG DAMP-related signaling, infection would be expected to increase the production of free hemoglobin, hemoglobin-haptoglobin complexes $(9,11)$ and activated CD163 macrophages, a major cellular producer of ferritin $(12,43)$. This increased ferritin production could then further amplify the inflammatory loop (12, 43) as well as directly alter lymphocyte function (47-53). Blue text refers to potential therapeutics targeted to steps in the pathway, including using intravenous gamma globulin (IVIG) to clear viral infection and CpG DNA, using plasma exchange (PLEX) for clearance of free hemoglobin and hemoglobin-haptoglobin complexes, as well as free ferritin, using specific anti-IFN- $\gamma$ antibodies, IL-1RA or IL-18-binding protein (IL-18 BP) or using glyburide to target inflammasome activation.

inhibition of a case of recurrent MAS with early-onset enterocolitis secondary to a gain of function mutation in NLRC4, a protein that activates the inflammasome (OMIM\#616050). When used in combination with other immunomodulatory therapy, it leads to rapid resolution of hyperferritinemia, enterocolitis and other signs of systemic inflammation (108). Currently, the HLH Society recommends cytotoxic regimens, which have recently come into question related to the considerable side effects $(78,103,104)$. Concurrent work at developing more targeted approaches include development of ATG to remove the T cells or NK cells directly $(104,105)$ or anti-IFN- $\gamma$ globulin to remove the soluble cytokine stimulus for ongoing macrophage activation (106).

\section{Conclusions}

Dynamic regulation of ferritin during normal iron metabolism is an essential host regulatory mechanism. Additional research on primary inflammatory disorders suggests that, in addition to this homeostatic role, ferritin may be a key marker of and pathogenic player in inflammatory pathology through its signaling as part of the innate immune response and modulation of lymphocyte function. Clinical practice supports this role, as it can be used as both a biomarker of disease progress and prognosis as well as a target for therapeutic intervention. However, the precise mechanism by which ferritin contributes to disease in sepsis, rheumatologic, immunologic and malignant disorders remains elusive. We hope that this review highlights what is known about ferritin's role as both marker for and mediator of disease pathology and that the proposed working models spur interest in future research.

\section{Funding}

This work was funded by NIGMS via R01GM108168.

Conflicts of Interest statement: The authors declared no conflicts of interest.

\section{References}

1 Cricthon, R. R. and Chaloteaux-Wauters, M. 1987. Iron transport and storage. Eur. J. Biochem. 164:485.

2 Gozzelino, R. and Soares, M. P. 2014. Coupling heme and iron metabolism via ferritin H chain. Antioxid. Redox Signal. 20:1754.

3 Cohen, L. A., Gutierrez, L., Weiss, A. et al. 2010. Serum ferritin is derived primarily from macrophages through a nonclassical secretory pathway. Blood 116:1574.

4 Kato, J., Kobune, M., Ohkubo, S. et al. 2007. Iron/IRP-1-dependent regulation of mRNA expression for transferrin receptor, DMT1 and ferritin during human erythroid differentiation. Exp. Hematol. 35:879.

5 Harrison, P. M. and Arosio, P. 1996. The ferritins: molecular properties, iron storage function and cellular regulation. Biochim. Biophys. Acta 1275:161.

6 Thomson, A. M., Cahill, C. M., Cho, H. H. et al. 2005. The acute box cis-element in human heavy ferritin mRNA 5'-untranslated region is a unique translation enhancer that binds poly(C-binding proteins. J. Biol. Chem. 280:30032.

7 Fahmy, M. and Young, S. P. 1993. Modulation of iron metabolism in monocyte cell line U937 by inflammatory cytokines: changes in transferrin uptake, iron handling and ferritin mRNA. Biochem. J. 296(Pt 1):175. 
8 Mikhael, M., Kim, S. F., Schranzhofer, M. et al. 2006. Iron regulatory protein-independent regulation of ferritin synthesis by nitrogen monoxide. FEBS J. 273:3828.

9 Korolnek, T. and Hamza, I. 2015. Macrophages and iron trafficking at the birth and death of red cells. Blood 125:2893.

10 Delabya, C., Pilarda, N., Hetetb, G. et al. 2005. A physiological model to study iron recycling in macrophages. Exp. Cell Res. 310:43.

11 Moldawer, L. L., Marano, M. A., Wei, H. et al. 1989. Cachectin/ tumor necrosis factor-alpha alters red blood cell kinetics and induces anemia in vivo. FASEB J. 3:1637.

12 Dinkla, S., van Eijk, L. T., Fuchs, B. et al. 2016. Inflammationassociated changes in lipid composition and the organization of the erythrocyte membrane. BBA Clin. 5:186.

13 Piagnerelli, K., Boudjeltia, M., Brohee, D. et al. 2003. Alterations of red blood cell shape and sialic acid membrane content in septic patients. Crit. Care Med. 31:2156.

14 Todd, J. C. 3rd and Mollitt, D. L. 1995. Effect of sepsis on erythrocyte intracellular calcium homeostasis. Crit. Care Med. 23:459.

15 Reggiori, G., Occhipinti, G., De Gasperi, A., Vincent, J. L. and Piagnerelli, M. 2009. Early alterations of red blood cell rheology in critically ill patients. Crit. Care Med. 37:3041.

16 Mendonça, R., Silveira, A. A. and Conran, N. 2016. Red cell DAMPs and inflammation. Inflamm. Res. 65:665.

17 Schaer, C. A., Schoedon, G., Imhof, A., Kurrer, M. O. and Schaer, D. J. 2006. Constitutive endocytosis of CD163 mediates hemoglobin-heme uptake and determines the noninflammatory and protective transcriptional response of macrophages to hemoglobin. Circ. Res. 99:943.

18 Tenhunen, R., Marver, H. S. and Schmid, R. 1968. The enzymatic conversion of heme to bilirubin by microsomal heme oxygenase. Proc. Natl Acad. Sci. USA 61:748.

19 Leimberg, M. J., Prus, E., Konijn, A. M. and Fibach, E. 2008. Macrophages function as a ferritin iron source for cultured human erythroid precursors. J. Cell. Biochem. 103:1211.

20 Donovan, A., Lima, C. A., Pinkus, J. L. et al. 2005. The iron exporter ferroportin/Slc40a1 is essential for iron homeostasis. Cell Metab. 1:191.

21 Corna, G., Caserta, I., Monno, A. et al. 2016. The repair of skeletal muscle requires iron recycling through macrophage ferroportin. $J$. Immunol. 197:1914.

22 Torti, F. M. and Torti, S. V. 2002. Regulation of ferritin genes and protein. Blood 99:3505.

23 Podmore, C., Meidtner, K., Schulze, M. B. et al. 2016. Association of multiple biomarkers of iron metabolism and type 2 diabetes: The EPIC-InterAct Study. Diabetes Care 39:572.

24 Marques, L., Negre-Salvayre, A., Costa, L. and CanonneHergaux, F. 2016. Iron gene expression profile in atherogenic Mox macrophages. Biochim. Biophys. Acta 1862:1137.

25 Silvestre, O. M., Gonçalves, A., Nadruz, W. Jr et al. 2017. Ferritin levels and risk of heart failure-the Atherosclerosis Risk in Communities Study. Eur. J. Heart Fail. 19:340.

26 Pieracci, F. M. and Barie, P. S. 2005. Iron and the risk of infection. Surg. Infect. (Larchmt.) 6(Suppl. 1):S41.

27 Wooldridge, K. G. and Williams, P. H. 1993. Iron uptake mechanisms of pathogenic bacteria. FEMS Microbiol. Rev. 12:325.

28 Letendre, E. D. and Holbein, B. E. 1984. Mechanism of impaired iron release by the reticuloendothelial system during the hypoferremic phase of experimental Neisseria meningitidis infection in mice. Infect. Immun. 44:320.

29 Sazawal, S., Black, R. E., Kabole, I., Dutta, A., Dhingra, U. and Ramsan, M. 2014. Effect of iron/folic Acid supplementation on the outcome of malaria episodes treated with sulfadoxine-pyrimethamine. Malar. Res. Treat. 2014:625905.

30 Kent, S. and Dunn, D. 1993. Etiology of hypoferremia in a recently sedentary Kalahari village. Am. J. Trop. Med. Hyg. 48:554.

31 Alvarez-Hernández, X., Licéaga, J., McKay, I. C. and Brock, J. H. 1989. Induction of hypoferremia and modulation of macrophage iron metabolism by tumor necrosis factor. Lab. Invest. 61:319.

32 Corna, G., Campana, L., Pignatti, E. et al. 2010. Polarization dictates iron handling by inflammatory and alternatively activated macrophages. Haematologica 95:1814.
33 Recalcati, S., Locati, M., Marini, A. et al. 2010. Differential regulation of iron homeostasis during human macrophage polarized activation. Eur. J. Immunol. 40:824.

34 Seifert, M., Nairz, M., Schroll, A., Schrettl, M., Haas, H. and Weiss, G. 2008. Effects of the Aspergillus fumigatus siderophore systems on the regulation of macrophage immune effector pathways and iron homeostasis. Immunobiology 213:767.

35 Konijn, A. M., Carmel, N., Levy, R. and Hershko, C. 1981. Ferritin synthesis in inflammation. II. Mechanism of increased ferritin synthesis. Br. J. Haematol. 49:361.

36 Recalcati, S., Invernizzi, P., Arosio, P. and Cairo, G. 2008. New functions for an iron storage protein: the role of ferritin in immunity and autoimmunity. J. Autoimmun. 30:84.

37 Kwak, E. L., Larochelle, D. A., Beaumont, C., Torti, S. V. and Torti, F. M. 1995. Role for NF-kappa B in the regulation of ferritin $\mathrm{H}$ by tumor necrosis factor-alpha. J. Biol. Chem. 270:15285.

38 Pham, C. G., Bubici, C., Zazzeroni, F. et al. 2004. Ferritin heavy chain upregulation by NF-kappaB inhibits TNFalpha-induced apoptosis by suppressing reactive oxygen species. Cell 119:529.

39 Wei, Y., Miller, S. C., Tsuji, Y., Torti, S. V. and Torti, F. M. 1990. Interleukin 1 induces ferritin heavy chain in human muscle cells. Biochem. Biophys. Res. Commun. 169:289.

40 Rogers, J. T., Andriotakis, J. L., Lacroix, L., Durmowicz, G. P., Kasschau, K. D. and Bridges, K. R. 1994. Translational enhancement of $\mathrm{H}$-ferritin mRNA by interleukin-1 beta acts through 5 leader sequences distinct from the iron responsive element. Nucleic Acids Res. 22:2678.

41 Huang, B. W., Miyazawa, M. and Tsuji, Y. 2014. Distinct regulatory mechanisms of the human ferritin gene by hypoxia and hypoxia mimetic cobalt chloride at the transcriptional and post-transcriptional levels. Cell Signal. 26:2702.

42 Tran, T. N., Eubanks, S. K., Schaffer, K. J., Zhou, C. Y. and Linder, M. C. 1997. Secretion of ferritin by rat hepatoma cells and its regulation by inflammatory cytokines and iron. Blood 90:4979.

43 Cragg, S. J., Wagstaff, M. and Worwood, M. 1981. Detection of a glycosylated subunit in human serum ferritin. Biochem. J. 199:565.

44 Ghosh, S., Hevi, S. and Chuck, S. L. 2004. Regulated secretion of glycosylated human ferritin from hepatocytes. Blood 103:2369.

45 Fautrel, B., Moël, G., Saint-Marcoux, B. et al. 2001. Diagnostic value of and glycosylated ferritin in adult onset Still's disease. J. Rheumatol. 28:12.

46 Fautrel, B. 2008. Adult-onset Still disease. Best Pract. Res. Clin. Rheumatol. 22:773.

47 Van Reeth, C. Le Moel, G., Lasne, Y. et al. 1994. Serum ferritin and isoferritins are tools for diagnosis of active adult Still's disease. J. Rheumatol. 21:890.

48 Higashi, S., Ota, T. and Eto, S. Biochemical analysis of ferritin subunits in sera from adult Still's disease patients. Rheumatol Int. 15:45.

49 Zollner, R. C., Kern, P., Steininger, H. et al. 1997. Hyperferritinemia in Still syndrome in the adult and reactive hemophagocytic syndrome. Med. Klin. (Munich) 92:494.

50 Lambotte, O., Cacoub, P., Costedoat, N. et al. 2003. High ferritin and low glycosylated ferritin may also be a marker of excessive macrophage activation. J. Rheumatol. 30:1027.

51 Wang, Z., Wang, Y. N., Feng, C. C., Tian, L. P. and Chen, X. 2009. The early diagnosis and clinical analysis of 57 cases of acquired hemophagocytic lymphohistiocytosis. Zhonghua Nei Ke Za Zhi 48:312.

52 Ben m'rad, M., Leclerc-Mercier, S., Blanche, P. et al. 2009. Druginduced hypersensitivity syndrome: clinical and biologic disease patterns in 24 patients. Medicine (Baltimore) 88:131.

53 Lambotte, O., Costedoat-Chalumeau, N., Amoura, Z., Piette, J. C. and Cacoub, P. 2002. Drug-induced hemophagocytosis. Am J. Med. 112:592.

54 Worwood, M., Cragg, S. J., Wagstaff, M. and Jacobs, A. 1979. Binding of human serum ferritin to concanavalin A. Clin. Sci. (Lond.) 56:83.

55 Muylle, L., Blockx, P. and Becquart, D. 1986. Binding of serum ferritin to concanavalin $\mathrm{A}$ in patients with malignancy. Biomed. Pharmacother. 40:225. 
56 Takakuwa, Y., Miyazawa, K., Yoshikawa, O. and Toyama, K. 1994. The clinical significance of glycosylated ferritin in iron overloads and hematopoietic malignancies. Rinsho Ketsueki 35:744.

57 Vignes, S., Le Moël, G., Fautrel, B., Wechsler, B., Godeau, P. and Piette, J. C. 2000. Percentage of glycosylated serum ferritin remains low throughout the course of adult onset Still's disease. Ann. Rheum. Dis. 59:347.

58 Fan, Y., Yamada, T., Shimizu, T. et al. 2009. Ferritin expression in rat hepatocytes and Kupffer cells after lead nitrate treatment. Toxicol. Pathol. 37:209.

59 Zager, R. A., Johnson, A. C. and Hanson, S. Y. 2004. Parenteral iron nephrotoxicity: potential mechanisms and consequences. Kidney Int. 66:144.

60 Wesselius, L. J., Nelson, M. E. and Skikne, B. S. 1994. Increased release of ferritin and iron by iron-loaded alveolar macrophages in cigarette smokers. Am. J. Respir. Crit. Care Med. 150:690.

61 Ferring-Appel, D., Hentze, M. W. and Galy, B. 2009. Cellautonomous and systemic context-dependent functions of iron regulatory protein 2 in mammalian iron metabolism. Blood 113:679.

62 Cazzola, M., Bergamaschi, G., Tonon, L. et al. 1997. Hereditary hyperferritinemia-cataract syndrome: relationship between phenotypes and specific mutations in the iron-responsive element of ferritin light-chain mRNA. Blood 90:814

63 Colafrancesco, S., Priori, R., Alessandri, C. et al. 2014. sCD163 in AOSD: a biomarker for macrophage activation related to hyperferritinemia. Immunol. Res. 60:177.

64 Schaer, D. J., Schaer, C. A., Schoedon, G., Imhof, A. and Kurrer, M. O. 2006. Hemophagocytic macrophages constitute a major compartment of heme oxygenase expression in sepsis. Eur. J. Haematol. 77:432.

65 Ruddell, R. G., Hoang-Le, D., Barwood, J. M. et al. 2009. Ferritin functions as a proinflammatory cytokine via iron-independent protein kinase $\mathrm{C}$ zeta/nuclear factor kappaB-regulated signaling in rat hepatic stellate cells. Hepatology 49:887.

66 Freeman, G. J., Casasnovas, J. M., Umetsu, D. T. and DeKruyff, R. H. 2010. TIM genes: a family of cell surface phosphatidylserine receptors that regulate innate and adaptive immunity. Immunol. Rev. 235:172

67 Fargion, S., Fracanzani, A. L., Brando, B., Arosio, P., Levi, S. and Fiorelli, G. 1991. Specific binding sites for $\mathrm{H}$-ferritin on human lymphocytes: modulation during cellular proliferation and potential implication in cell growth control. Blood 78:1056.

68 Broxmeyer, H. E., Williams, D. E., Geissler, K. et al. 1989. Suppressive effects in vivo of purified recombinant human $\mathrm{H}$-subunit (acidic) ferritin on murine myelopoiesis. Blood 73:74.

69 Yamashita, M., Harada, G., Matsumoto, S. E. et al. 2014. Suppression of immunoglobulin production in human peripheral blood mononuclear cells by monocytes via secretion of heavychain ferritin. Immunobiology 219:149.

70 Li, R., Luo, C., Mines, M., Zhang, J. and Fan, G. H. 2006. Chemokine CXCL12 induces binding of ferritin heavy chain to the chemokine receptor CXCR4, alters CXCR4 signaling, and induces phosphorylation and nuclear translocation of ferritin heavy chain. J. Biol. Chem. 281:37616.

71 Gray, C. P., Arosio, P. and Hersey, P. 2002. Heavy chain ferritin activates regulatory $T$ cells by induction of changes in dendritic cells. Blood 99:3326.

72 Harada, T., Baba, M., Torii, I. and Morikawa, S. 1987. Ferritin selectively suppresses delayed-type hypersensitivity responses at induction or effector phase. Cell. Immunol. 109:75.

73 Wigginton, J. M. 1995. Reversal of ferritin-mediated immunosuppression by levamisole: a rationale for its application to management of the acquired immune deficiency syndrome (AIDS). Med. Hypotheses 44:85.

74 Carcillo, J. A., Sward, K., Halstead, E.S. et al. 2016. A systemic inflammation mortality risk assessment contingency table for severe sepsis. Pediatr. Crit. Care Med. 18:143.

75 Garcia, P. C., Longhi, F., Branco, R. G., Piva, J. P., Lacks, D. and Tasker, R. C. 2007. Ferritin levels in children with severe sepsis and septic shock. Acta Paediatr. 96:1829.

76 Bennett, T. D., Hayward, K. N., Farris, R. W., Ringold, S., Wallace, C. A. and Brogan, T. V. 2011. Very high serum ferritin levels are associated with increased mortality and critical care in pediatric patients. Pediatr. Crit. Care Med. 12:e233.

77 Tonial, C. T., Garcia, P. C. R., Schweitzer, L. C. et al. 2017. Cardiac dysfunction at echocardiogram and ferritin as early markers of severity in pediatric sepsis. J. Pediatr. (Rio J.) S0021-7557:30032.

78 Castillo, L. and Carcillo, J. 2009. Secondary hemophagocytic lymphohistiocytosis and severe sepsis/ systemic inflammatory response syndrome/multiorgan dysfunction syndrome/macrophage activation syndrome share common intermediate phenotypes on a spectrum of inflammation. Pediatr. Crit. Care Med. 10:387.

79 Rosário, C., Zandman-Goddard, G., Meyron-Holtz, E. G., D'Cruz, D. P. and Shoenfeld, Y. 2013. The hyperferritinemic syndrome: macrophage activation syndrome, Still's disease, septic shock and catastrophic antiphospholipid syndrome. BMC Med. 11:185.

80 Rosário, C. and Shoenfeld, Y. 2014. The hyperferritinemic syndrome. Isr. Med. Assoc. J. 16:664.

81 Jordan, M. B., Allen, C. E., Weitzman, S., Filipovich, A. H. and McClain, K. L. 2011. How I treat hemophagocytic lymphohistiocytosis. Blood 118:4041

82 Zur Stadt, U., Beutel, K., Kolberg, S. et al. 2006. Mutation spectrum in children with primary hemophagocytic lymphohistiocytosis: molecular and functional analyses of PRF1, UNC13D, STX11, and RAB27A. Hum. Mutat. 27:62.

83 Behrens, E. M. 2008. Macrophage activation syndrome in rheumatic disease: what is the role of the antigen presenting cell? Autoimmun. Rev. 7:305.

84 Tang, Y., Xu, X., Song, H. et al. 2008. Early diagnostic and prognostic significance of a specific $T_{h} 1 / T_{h} 2$ cytokine pattern in children with haemophagocytic syndrome. Br. J. Haematol. 143:84.

85 Akashi, K., Hayashi, S., Gondo, H. et al. 1994. Involvement of interferon-gamma and macrophage colony-stimulating factor in pathogenesis of haemophagocytic lymphohistiocytosis in adults. Br. J. Haematol. 87:243.

86 Henter, J. I., Elinder, G., Söder, O., Hansson, M., Andersson, B. and Andersson, U. 1991. Hypercytokinemia in familial hemophagocytic lymphohistiocytosis. Blood 78:2918.

87 Grom A. A. 2016. Macrophage activation syndrome. In Petty, R. E., Laxer, R. M., Lindsley, C. B. and Wedderburn, L., eds, Textbook of Pediatric Rheumatology, p. 642, Elsevier Inc., Philadelphia, PA.

88 Zhang, K., Jordan, M. B., Marsh, R. A. et al. 2011. Hypomorphic mutations in PRF1, MUNC13-4, and STXBP2 are associated with adult-onset familial HLH. Blood 118:5794.

89 Cetica, V., Sieni, E., Pende, D. et al. 2016. Genetic predisposition to hemophagocytic lymphohistiocytosis: report on 500 patients from the Italian registry. J. Allergy Clin. Immunol. 137:188.

90 Kernan, K., Ghaloul-Gonzalez, L., Sethi, R. et al. 2016. Genetic variants associated with hyperinflammation in septic shock. Crit. Care Med. 44:427.

91 Behrens, E. M., Canna, S. W., Slade, K. et al. 2011. Repeated TLR9 stimulation results in macrophage activation syndrome-like disease in mice. J. Clin. Invest. 121:2264.

92 Tsujimoto, H., Ono, S., Matsumoto, A. et al. 2006. A critical role of $\mathrm{CpG}$ motifs in a murine peritonitis model by their binding to highly expressed toll-like receptor-9 on liver NKT cells. J. Hepatol. 45:836.

93 Petrasek, J., Dolganiuc, A., Csak, T., Kurt-Jones, E. A. and Szabo, G. 2011. Type I interferons protect from Toll-like receptor 9-associated liver injury and regulate IL-1 receptor antagonist in mice. Gastroenterology 140:697.

94 Muruve, D. A., Pétrilli, V., Zaiss, A. K. et al. 2008. The inflammasome recognizes cytosolic microbial and host DNA and triggers an innate immune response. Nature 452:103.

95 Elmaagacli, A., Steckel, N., Koldehoff, M. et al. 2010. Toll-likereceptor expression and cellular immune reconstitution in AMLpatients with elevated serum ferritin levels after allogeneic transplant. Blood 116:1049.

96 Shakoory, B., Carcillo, J. A., Chatham, W. W. et al. 2016. Interleukin-1 receptor blockade is associated with reduced mortality in sepsis patients with features of macrophage activation syndrome: reanalysis of a prior phase III trial. Crit. Care Med. 44:275. 
97 Lamkanfi, M., Mueller, J. L., Vitari, A. C. et al. 2009. Glyburide inhibits the Cryopyrin/Nalp3 inflammasome. J. Cell Biol. 187:61.

98 Coll, R. C., Robertson, A. A., Chae, J. J. et al. 2015. A smallmolecule inhibitor of the NLRP3 inflammasome for the treatment of inflammatory diseases. Nat. Med. 21:248.

99 Li, J., Wang, Q., Zheng, W. et al. 2014. Hemophagocytic lymphohistiocytosis: clinical analysis of 103 adult patients. Medicine (Baltimore) 93:100

100 Davì, S., Minoia, F., Pistorio, A. et al.; Paediatric Rheumatology International Trials Organisation, the Childhood Arthritis and Rheumatology Research Alliance, the Pediatric Rheumatology Collaborative Study Group, and the Histiocyte Society. 2014 Performance of current guidelines for diagnosis of macrophage activation syndrome complicating systemic juvenile idiopathic arthritis. Arthritis Rheumatol. 66:2871

101 Boom, V., Anton, J., Lahdenne, P. et al. 2015. Evidence-based diagnosis and treatment of macrophage activation syndrome in systemic juvenile idiopathic arthritis. Pediatr. Rheumatol. Online J. 13:55.

102 Henter, J. I., Horne, A., Aricó, M. et al. 2007. HLH-2004: diagnostic and therapeutic guidelines for hemophagocytic lymphohistiocytosis. Pediatr. Blood Cancer 48:124.
103 Haytoglu, Z., Yazici, N. and Erbay, A. 2017. Secondary hemophagocytic lymphohistiocytosis: do we really need chemotherapeutics for all patients? J. Pediatr. Hematol. Oncol. 39:e106.

104 Demirkol, D., Yildizdas, D., Bayrakci, B. et al.; Turkish Secondary HLH/MAS Critical Care Study Group. 2012. Hyperferritinemia in the critically ill child with secondary hemophagocytic lymphohistiocytosis/sepsis/multiple organ dysfunction syndrome/macrophage activation syndrome: what is the treatment? Crit. Care 16:R52

105 Coca, A., Bundy, K. W., Marston, B., Huggins, J. and Looney, R. J. 2009. Macrophage activation syndrome: serological markers and treatment with anti-thymocyte globulin. Clin. Immunol. 132:10.

106 Horne, A., Wickström, R., Jordan, M. B. et al. 2017. How to treat involvement of the central nervous system in hemophagocytic lymphohistiocytosis? Curr. Treat. Options Neurol. 19:3.

107 Dinarello, C. A., Novick, D., Kim, S. and Kaplanski, G. 2013. Interleukin-18 and IL-18 binding protein. Front. Immunol. 4:289.

108 Canna, S. W., Girard, C., Malle, L. et al. 2017. Life-threatening NLRC4-associated hyperinflammation successfully treated with IL-18 inhibition. J. Allergy Clin. Immunol. 139:1698 